\title{
Factors affecting falls in community-dwelling individuals with stroke in Singapore after hospital discharge
}

Lay Fong $\underline{C h i n}^{1}$, BSc (Phty), MPhty, Juliana $Y Y \underline{\text { Wang}}^{1}$, BPhty, Dipphty, Cheng Hong Ong ${ }^{1}$, BPhty, Wing Kuen Lee ${ }^{1}$, BSc (Phty), MClinRehab, Keng He Kong ${ }^{1}$, MBBS, MRCP

INTRODUCTION This study aimed to investigate the factors affecting the incidence of falls among individuals with stroke living in the community one year after discharge from a rehabilitation hospital in Singapore.

METHODS A cross-sectional telephone survey of individuals with stroke living in the community was carried out one year after discharge. The interview covered aspects such as incidence and circumstances of fall, use of walking aids, and presence of environmental obstacles. Each participant's case record was retrospectively reviewed using discharge Fugl-Meyer (FM) assessment of the upper and lower limbs, functional independence measure (FIM) and Berg Balance Scale (BBS).

RESULTS A total of 126 individuals with stroke were interviewed. Overall, $24 \%$ fell in the year following their discharge. Factors associated with falls were longer length of hospital stay, lower BBS and lower-limb FM scores, and lower discharge FIM scores for the Bladder and Bowel Management, Transfer, Mobility, Communication, and Social Cognition domains $(p<0.05)$. The fallers were more likely to use walking aids, and required help with basic activities of daily living after discharge $(p<0.05)$. Multivariate logistic regression analysis revealed that only the Transfer domain was an independent factor for falls.

CONCLUSION Discharge FIM outcomes, especially for the Transfer domain, can be used to identify communitydwelling individuals with stroke who have a high fall risk after discharge. Identification of such individuals will enable early fall prevention management, which will in turn minimise fall events in the community.

Keywords: community, discharge, falls, stroke

\section{INTRODUCTION}

Falls among community-dwelling individuals with stroke have been widely reported in the literature, with the incidence of falls found to be $37 \%-55 \% .^{(1-11)}$ It has also been reported that over a period of four to six months, community-dwelling individuals with stroke were two times more likely to fall than the average elderly population. ${ }^{(4,12)}$ Individuals with stroke have a higher risk of falls because of persisting neurological impairments such as motor, ${ }^{(3,13)}$ sensory $^{(7)}$ and vision ${ }^{(11)}$ deficits resulting from their strokes. These deficits can affect their balance and mobility, and hence increase fall risk. ${ }^{(11)}$ In addition, other psychological factors, such as depressive symptoms, have also been found to be associated with an increased fall risk in community-dwelling individuals with stroke. ${ }^{(12)}$ Lamb et al found that over a period of 12 months, stroke individuals who had only residual non-motor symptoms, or a combination of non-motor and motor symptoms, had a higher fall risk of $53.3 \%$ and $62.2 \%$, respectively, compared to the fall risk of $39.8 \%$ in normal elderly. ${ }^{(7)}$

The consequences of falls can have a negative physical and psychosocial impact on individuals with stroke. Physical injuries in individuals with stroke after falls include fractures ${ }^{(3,6,8)}$ and soft tissue injuries..$^{(8,14)}$ The incidence of injuries in individuals with stroke after falling has been found to be $15 \%-50 \%{ }^{(3,7,8,13)}$ Hip fractures are the most common fractures reported; a $2.1 \%$ rate of hip fractures has been reported to occur in individuals with stroke after a fall. ${ }^{(3)}$ There is also a two- to four-fold increase in the risk of hip fractures in individuals with stroke than in those without. ${ }^{(15-17)}$

Examples of the negative psychosocial impact of falls on individuals with stroke include fear of falling, reduced mobility, greater disability, depression, increased stress experienced by the carer, and social deprivation. ${ }^{(12,14,18)}$ Mackintosh et al reported in a 2005 study that $44 \%$ of stroke individuals who fell restricted their activities due to a fear of falling. ${ }^{(8)}$ Belgen et al in 2006 also reported that individuals with stroke who fell were 5.6 times more likely to be afraid of falling. ${ }^{(2)}$ This fear of falling leads to reduced falls-related self-efficacy, which in turn leads to deconditioning and a reduction in physical activity, resulting in a loss of functional independence. (2) Additionally, community-dwelling individuals with stroke who have fallen have also been found to be less socially active and more depressed. ${ }^{(14)}$ Depression and reduction in social activity can result in further deconditioning

\footnotetext{
Tan Tock Seng Hospital Rehabilitation Centre, Singapore

Correspondence: Ms Chin Lay Fong, Principal Physiotherapist, Tan Tock Seng Rehabilitation Centre, 17 Ang Mo Kio Avenue 9 , Singapore 569766. lay_fong_chin@ttsh.com.sg
} 
and reduction in physical activity, hence further increasing the risk of falls in these individuals. ${ }^{(17)}$ In view of the prevalence of high fall risk and its negative impacts, information on the factors affecting falls in community dwelling individuals with stroke is important. With this information, identification of high-fall risk individuals with stroke, and implementation of timely and effective falls management strategies can be performed to prevent and minimise the occurrence of falls in such individuals.

According to the literature, factors such as poorer balance, ${ }^{(2,8,9,14)}$ reduction in walking speed, ${ }^{(8)}$ reduced level of activity, ${ }^{(8)}$ increased medications intake, ${ }^{(2,8)}$ greater mobility deficits, ${ }^{(13)}$ reduced arm function, ${ }^{(13)}$ reduction in ability to perform activities of daily living (ADL), ${ }^{(13,14)}$ incidence of fall during hospitalisation, ${ }^{(9,14)}$ higher levels of anxiety, ${ }^{(2)}$ and depression ${ }^{(2,12)}$ are associated with increased falls in community-dwelling individuals with stroke. However, there is to date a dearth of information on the prevalence of falls and the factors associated with falls in community-dwelling individuals with stroke in Singapore. This study thus sought to fill this gap in information by evaluating the rate of falls and the factors associated with it in a cohort of individuals with stroke who were successfully discharged back to the community after inpatient rehabilitation. The identification of high-fall risk individuals and the implementation of timely fall management strategies can be carried out during discharge planning and after discharge.

\section{METHODS}

Consecutive individuals with stroke, discharged from Tan Tock Seng Hospital Rehabilitation Centre (TTSHRC) between September 2008 and July 2009, were invited to participate in this study via telephone interviews one year after hospital discharge. TTSHRC is the largest tertiary rehabilitation centre in Singapore, with 50 inpatient beds dedicated to stroke rehabilitation. The list of individuals with stroke was extracted from the TTSHRC database. This study included individuals with stroke, for whom data sets were complete, who were at least 21 years old and living in the community for at least six months post hospital discharge. The exclusion criteria were: (a) recurrent stroke; (b) concurrent neurological disease, such as Parkinson's disease, Guillain-Barré syndrome and multiple sclerosis; (c) any surgical procedure done in the 12 months preceding the telephone interview; (d) lower extremity fractures prior to stroke events; and (e) any active major orthopaedic problem, such as amputation of limbs prior to stroke events, which might predispose the individual to falls. This study was approved by the National Healthcare Group Domain Specific Review Board, Singapore.

Patients who satisfied the aforementioned criteria were contacted and interviewed via telephone by four physiotherapists from TTSHRC one year after hospital discharge. If the patients were not contactable after three call attempts, their names would be taken off the list. If the patients had difficulties with speech and understanding, their caregivers were allowed to participate in the telephone interviews on their behalf. A standardised English or Mandarin script on the description, purpose and procedure of the study was verbally administered according to the interviewee's preferred language. Participants' verbal consent was obtained and recorded upon agreement to take part in the telephone interview. All participants were informed of their liberty to discontinue the telephone interview if they decide to withdraw from the study. For the purposes of this study, a fall is defined as "an episode of unintentionally coming to rest on the ground or a lower surface that is not the result of dizziness, fainting, sustaining a violent blow, loss of consciousness, or other overwhelming external factors"..19) Based on each participant's history of falls, participants were categorised as either fallers (if they had fallen one or more times during the one-year post-discharge period) or non-fallers (if they had not fallen during the study period).

Information on demographic characteristics such as age, side of weakness (left/right/bilateral) and date of stroke onset was obtained during the telephone interview. Personal questions were asked and the answers were recorded in a binary fashion (i.e. yes/no) during the telephone interview. These questions included "Can you see clearly?", "Do you have more than five medical conditions?", and "Do you take more than five different medications every day?" Physical-related questions, such as "Do you use a walking stick/quad stick/walking frame indoors?", "Do you use a walking stick/quad stick/walking frame outdoors?", "Do you use a wheelchair to move about indoors?", "Do you use a wheelchair to move about outdoors?", "Do you need someone to help you to bathe or put on your shirt/pants?", and "Do you go out on your own?", were asked and the answers were recorded in a binary fashion during the telephone interview. The questions on the use of walking aids and wheelchairs for mobility purposes were not mutually exclusive. Questions on living and environmental factors were asked and the answers were recorded in a binary fashion during the telephone interview. This included questions like "Do you live alone? If no, who do you live with? (Family, friends, paid help, others)", "Is your flat on the same level as a lift landing?" (Participants living in landed properties were entered as located on the same level as the lift landing during data entry), "Do you need to overcome any steps within your house?", "Do you need to climb up any steps to get into your house?", "Do you need to cross over any kerb to get into the bathroom/toilet within your house?", "Is there any clutter in your house that might potentially cause you to fall?", and "Is your house well lit?" Questions regarding psychological factors were also asked and the answers were recorded in a binary fashion. Questions included "Are you afraid of falling?", and "In general, do you feel sad or depressed?" Binary questions about whether the participants had fallen during hospitalisation from the time 
of acute admission to discharge were also asked during the interview. Participants were likewise asked whether they had fallen during the 12-month period after hospital discharge. Falls history in the community was provided by participants in open-ended answers to questions such as "How many times have you fallen?", "Where did you fall?", "What were you doing when you fell?", and "How did you fall?"

Based on the participants' histories of falls, fall locations were categorised into these six groups: toilet, bedroom, living room, kitchen, within the home (i.e. anywhere else within the home), and outdoors. Activities during falls were categorised into four main types of activities: walking, transfer, toileting/showering, and others. Based on the fall histories, the reasons for falls were categorised into eight groups: loss of balance (i.e. participants stated that they had lost balance and fell), impulsivity (i.e. participants/carers reported that they/the participants acted against advice and fell), poor safety precautions (e.g. did not put on brakes before transfer), poor handling by carers (i.e. use of wrong handling techniques), poor attention to task (i.e. participant's lack of attention to a task led to the fall), poor vision (i.e. fell because of inability to see well), poor lighting (i.e. fell because it was dark), and others (i.e. reasons that did not fit into the other aforementioned categories).

Discharge outcome measures such as upper limb FuglMeyer (ULFM) and lower limb Fugl-Meyer (LLFM) assessments, functional independence measure (FIM), and Berg Balance Scales (BBS) were routinely captured at discharge and recorded in the TTSHRC database. This data was used for analysis in this study. ULFM assessment, which contains 33 items measuring movement, coordination and reflex action of the shoulder, elbow, forearm, wrist and hand, was used to measure upper limb motor recovery from hemiplegic stroke. Each item was scored on a three-point ordinal scale ranging $0-2$ (where $0=$ unable to perform, $1=$ able to perform partially, and 2 = able to perform fully). The highest possible ULFM score is $66 .{ }^{(20)}$ LLFM assessment was used to measure the lower limb motor recovery from hemiplegic stroke, and contained 17 items measuring movement, coordination and reflex action of the hip, knee and ankle. Each item was scored on a three-point ordinal scale (where $0=$ unable to perform, 1 = able to perform partially, and 2 = able to perform fully). The highest possible LLFM score is $34 .^{(20)}$

FIM, comprising a total of 18 items, was used to assess the physical and cognitive ability of the participants at discharge. Of these 18 items, 13 pertained to physical assessment, and 5 to cognitive assessment. Items were scored based on the level of assistance an individual required to perform ADL. The scoring scale for each item ranged from 1 (denoting total dependence) to 7 (denoting total independence). ${ }^{(21,22)}$ The 18 items were categorised into the following domains for data analysis: Self-Care, Bladder and Bowel Management, Transfer, Mobility, Communication, and Social Cognition.
BBS was used to measure the participants' balance abilities with decreasing base of support. BBS comprised a total of 14 items that were graded on a scale ranging from 0 to 4 , where 1 indicated an inability to perform the task, and 4 represented the ability to perform the task independently. The highest possible score is 56 points ${ }^{(23-26)}$ Initial assessment with BBS was performed while the participant was seated, with progression to assessment when the participant was standing, and finally to assessment when the participant was standing on one lower limb. Weight shifting, turning and reaching were also assessed.

Data analysis was performed using STATA version 10.0 for Windows (StataCorp, TX, USA). Descriptive statistics were used to describe the participants' demographics. Univariate logistic regression was performed to determine the factors associated with falls. Factors found to be associated with falls were further analysed using forward stepwise multivariate logistic regression to determine independent factors for falls. The level of significance for all data analysis was set at $\mathrm{p}<0.05$.

\section{RESULTS}

Although 337 individuals with stroke were admitted to TTSHRC during the period between September 2008 and July 2009, only 247 with completed discharge database information were available for analysis. Of these 247 individuals, 4 did not have any contact numbers, 16 passed away, and 1 was below the age of 21 years. Hence, only 226 individuals with stroke were available to take part in the one-year post-discharge telephone interviews. In all, only 126 community-dwelling individuals with stroke completed the telephone interviews - 10 were excluded from the study based on the exclusion criteria, 11 were admitted to nursing homes, 7 resided overseas, 23 refused to participate in the study, and 49 were not contactable. Of the 126 participants, $30(24 \%)$ reported falling during the one-year post-discharge period; 15 (12\%) fell only once and 15 (12\%) fell more than once. Altogether, there were 59 incidents of falls reported.

The demographic factors, length of stay, ULFM, LLFM, FIM, and BBS of all participants $(n=126)$ are listed in Table I. The median age of all participants was 61 years. Of the 126 participants, 88 were men and 38 were women; 86 participants suffered from ischaemic stroke, while 40 suffered from haemorrhagic stroke; 60 suffered from left-sided weakness, 63 from right-sided weakness and 3 from bilateral weakness. The median interval between stroke onset and the telephone interview was 13 months.

Fall locations, activity during fall and the reasons for falls are shown in Table II. Results showed that $86 \%$ of the falls occurred at home. The most common places of falls at home were the toilet $(36 \%)$, followed by the bedroom $(17 \%)$. The most frequent activity during falls was walking (48\%), followed by transfer $(20 \%)$. The most common reason for falls was a loss of balance $(56 \%)$, followed by impulsivity $(15 \%)$. 
Table I. Group comparison for demographic factors in individuals with stroke.

\begin{tabular}{|c|c|c|c|c|}
\hline Demographic & $\begin{array}{l}\text { Non-fallers } \\
(\mathrm{n}=96)\end{array}$ & $\begin{array}{l}\text { Fallers } \\
(n=30)\end{array}$ & $\begin{array}{c}\text { Total } \\
(n=126)\end{array}$ & p-value \\
\hline Age $^{*}$ (yrs) & $60(53,71)$ & $63(55,71)$ & $61(53,71)$ & 0.60 \\
\hline Male gender ${ }^{+}$ & $67(70)$ & $21(70)$ & $88(70)$ & 1.00 \\
\hline Infarct as cause of stroke ${ }^{+}$ & $66(69)$ & $20(67)$ & $86(68)$ & 0.80 \\
\hline Left-sided weakness ${ }^{+}$ & $49(51)$ & $11(37)$ & $60(48)$ & 0.08 \\
\hline $\begin{array}{l}\text { Interval between stroke onset } \\
\text { and interview* }{ }^{*}(\mathrm{mths})\end{array}$ & $13(13,13)$ & $13(13,14)$ & $13(13,14)$ & 0.40 \\
\hline Length of stay* (days) & $22(16,29)$ & $31(18,44)$ & $24(16,31)$ & $0.02^{*}$ \\
\hline ULFM $^{*}$ & $60(22,65)$ & $36(6,62)$ & $57(15,64)$ & 0.06 \\
\hline LLFM* $^{*}$ & $29(22,33)$ & $20(12,27)$ & $27(18,32)$ & $0.01^{*}$ \\
\hline BBS* & $34(11,48)$ & $13(5,39)$ & $29(7,44)$ & $0.003^{*}$ \\
\hline Total FIM score* & $89(71,98)$ & $72(60,89)$ & $88(69,96)$ & $0.007^{*}$ \\
\hline
\end{tabular}

${ }^{\star}$ Data is presented as median (interquartile range). ${ }^{\dagger}$ Data is presented as no. (\%). ${ }^{\ddagger} \mathrm{p}<0.05$ is significant.

BBS: Berg Balance Scale; FIM: functional independence measure; LLFM: lower limb Fugl-Meyer; ULFM: upper limb Fugl-Meyer

Hospital discharge FIM domains for all participants, including the faller and non-faller groups, are shown in Table III. With regard to FIM, the Bladder and Bowel Management, Transfer, Mobility, Communication, and Social Cognition domains were found to be associated with falls after discharge. Table IV shows the results of the telephone interview. The use of a walking aid indoors and outdoors, the use of a wheelchair outdoors, a lack of going outdoors alone, and help with bathing and dressing needed were associated with falls after discharge.

When all associated variables in the study were further analysed via forward stepwise multivariate logistic regression, discharge FIM scores revealed the Transfer domain as the only significant independent factor (odds ratio 0.78, $95 \%$ confidence interval $0.62-0.99 ; \mathrm{p}<0.05$ ).

\section{DISCUSSION}

The incidence of falls among the community-dwelling individuals with stroke in our study (24\%) was comparatively lower than that in other studies, which have reported an incidence of $37 \%-55 \% .{ }^{(1-11)}$ However, this difference might likely be due to the retrospective nature of our study, and the differences between the case mix of our study and other studies.

The results of our study revealed that most falls occurred at home $(86 \%)$. This is consistent with the findings of other studies, which reported an occurrence of approximately $80 \%$ among community-dwelling individuals with stroke. ${ }^{(2,6,8,13)}$ This high occurrence of falls within the home could be because these individuals spend most of their time at home either due to their limited functional mobility after stroke or because they are more cautious when they are outdoors.(10) Hence, emphasis should be placed on home assessment, home safety education and home environment modification during discharge planning in order to prevent falls from occurring at home. ${ }^{(10)}$ Attention should also be placed on safety in household
Table II. Fall locations, activity during fall and reason for falls.

\begin{tabular}{lc}
\hline Description & $\begin{array}{c}\text { Frequency (\%) of falls } \\
\text { ( } \mathbf{~ = ~ 5 9 ) ~}\end{array}$ \\
\hline Fall location & \\
Toilet & $21(35.6)$ \\
Bedroom & $10(16.9)$ \\
Living Room & $2(3.4)$ \\
Kitchen & $1(1.7)$ \\
Within the home* & $17(28.8)$ \\
Outdoors & $8(13.6)$ \\
Activity during fall & \\
Walking & $28(47.5)$ \\
Transfer & $12(20.3)$ \\
Toileting/showering & $9(15.3)$ \\
Others & $10(16.9)$ \\
Reason for fall & \\
Loss of balance & $33(55.9)$ \\
Impulsivity & $9(15.3)$ \\
Poor safety precautions & $8(13.6)$ \\
Poor handling by carer & $2(3.4)$ \\
Poor attention to task & $1(1.7)$ \\
Poor vision & $1(1.7)$ \\
Poor lighting & $1(1.7)$ \\
Others & $4(6.8)$ \\
\hline
\end{tabular}

${ }^{*}$ Excludes the toilet, bedroom, living room and kitchen.

toilets and bedrooms, since our results have shown that most falls occur at these locations within the house.

Our results also revealed that walking was the most common activity performed by the participants when they fell. This is in agreement with the findings of other studies. ${ }^{(4,8,14,27)}$ Conversely, it has been found that transfer, instead of walking, was the most common activity performed by individuals with stroke when they fell during their hospitalisation. ${ }^{(28,29)}$ During inpatient stay, the functional mobility of individuals with stroke is more confined and restrained by the settings and staff of the hospital. However, after discharge, the reduction in supervision and fewer restrictions in the home environments may cause them to push the limits of their functional mobility.

Poor balance has been consistently reported in many studies as one of the main factors leading to falls in community- 
Table III. Group comparison for functional independence measure (FIM) domains upon hospital discharge in individuals with stroke $(n=126)$.

\begin{tabular}{|c|c|c|c|c|}
\hline \multirow[t]{2}{*}{ Discharge FIM domains } & \multicolumn{3}{|c|}{ Median (interquartile range) } & \multirow[t]{2}{*}{ p-value } \\
\hline & Non-fallers $(n=96)$ & Fallers $(n=30)$ & Total $(n=126)$ & \\
\hline Self-care & $29(24,33)$ & $26(20,29)$ & $28(23,32)$ & 0.08 \\
\hline Bladder and Bowel Management & $8(6,10)$ & $6(4,9)$ & $8(6,10)$ & $0.05^{*}$ \\
\hline Transfer & $14(12,15)$ & $12(9,12)$ & $13(12,15)$ & $0.001^{*}$ \\
\hline Mobility & $8(5,10)$ & $6(4,8)$ & $8(5,9)$ & $0.02^{*}$ \\
\hline Communication & $14(11,14)$ & $14(8,14)$ & $14(10,14)$ & $0.05^{*}$ \\
\hline Social Cognition & $8(13,21)$ & $15(12,17)$ & $17(13,21)$ & $0.03^{*}$ \\
\hline
\end{tabular}

${ }^{*} p<0.05$ is significant.

Table IV. Group comparison for variables enquired during the telephone interview with individuals with stroke ( $\mathrm{n}=126$ ).

\begin{tabular}{|c|c|c|c|c|}
\hline \multirow[t]{2}{*}{ Variable } & \multicolumn{3}{|c|}{ No. of participants (\%) } & \multirow[t]{2}{*}{ p-value } \\
\hline & $\begin{array}{c}\text { Non-fallers } \\
(n=96)\end{array}$ & $\begin{array}{l}\text { Fallers } \\
(n=30)\end{array}$ & $\begin{array}{c}\text { Total } \\
(\mathrm{n}=126)\end{array}$ & \\
\hline \multicolumn{5}{|l|}{ Personal } \\
\hline Poor vision & $20(21)$ & $4(13)$ & 24 (19) & 0.40 \\
\hline$>5$ medical conditions & $10(10)$ & $3(10)$ & $13(10)$ & 0.90 \\
\hline Consume $>5$ types of medication daily & $35(36)$ & $14(47)$ & $49(39)$ & 0.30 \\
\hline \multicolumn{5}{|l|}{ Mobility } \\
\hline Use walking aid indoors & $15(16)$ & $12(40)$ & $27(21)$ & $0.006 *$ \\
\hline Use walking aid outdoors & $26(27)$ & $15(50)$ & $41(33)$ & $0.02^{*}$ \\
\hline Use wheelchair indoors & $13(14)$ & $6(20)$ & 19 (15) & 0.40 \\
\hline Use wheelchair outdoors & $23(24)$ & $13(43)$ & $36(29)$ & $0.04^{*}$ \\
\hline Does not go outdoors alone & $44(46)$ & $20(67)$ & $64(51)$ & $0.05^{*}$ \\
\hline \multicolumn{5}{|l|}{ Self-care } \\
\hline Live alone & $5(5)$ & $1(3)$ & $6(5)$ & 0.70 \\
\hline \multicolumn{5}{|l|}{ Home environment } \\
\hline Non-lift landing housing & $36(38)$ & $8(27)$ & $44(35)$ & 0.20 \\
\hline Need to climb stairs at home & $28(29)$ & $10(33)$ & $38(30)$ & 0.70 \\
\hline Raised level step into home & $47(49)$ & $13(43)$ & $60(48)$ & 0.60 \\
\hline Need to cross kerb within home & $63(66)$ & $21(70)$ & $84(67)$ & 0.70 \\
\hline Presence of clutter on floor & $6(6)$ & $5(17)$ & $11(9)$ & 0.09 \\
\hline Poor lighting within home & $4(4)$ & $3(10)$ & $7(6)$ & 0.20 \\
\hline \multicolumn{5}{|l|}{ Mood } \\
\hline Fear of falling & $46(48)$ & $15(50)$ & $61(48)$ & 0.80 \\
\hline Feel sad and depressed & $38(40)$ & $15(50)$ & $53(42)$ & 0.30 \\
\hline Fell during hospitalisation & $8(8)$ & 0 & $8(6)$ & 1.00 \\
\hline
\end{tabular}

${ }^{*} p<0.05$ is significant.

dwelling individuals with stroke..$^{(1,2,9,10)}$ The primary cause of poor balance in individuals with stroke is the presence of a central nervous system lesion, which causes their affected lower limbs to exhibit delayed and abnormal sequence of muscle activation during postural sways and challenges. ${ }^{(30)}$ These changes reduce the ability of individuals with stroke to adjust to and modify postural changes according to different task demands, thus placing them at a higher risk of falls.

Besides poorer balance, reduced motor function of the affected lower limb (i.e. lower LLFM score), reduced functional mobility (i.e. lower FIM scores in the Transfer and Mobility domains; requiring walking aids indoors and outdoors, requiring wheelchair outdoors) and reduced ability (i.e. lower total FIM score; requiring help in bathing and dressing) have been found to be associated with falls in our cohort. Our results are consistent with the findings of other studies. ${ }^{(3,6,9,11,13,14,27)}$
Interestingly, our results also reveal that reduced cognitive function (i.e. lower FIM score in the Social Cognition domain) is associated with falls. To the best of our knowledge, no studies have yet to examine the influence of reduced cognitive function on falls in community-dwelling individuals with stroke. However, there exists a plausible explanation as to why reduced cognitive function can lead to falls - individuals with stroke who have lowered cognitive function have reduced insight of their disabilities and reduced response inhibition; hence, they might attempt mobility beyond their abilities and against advice, thus resulting in falls. ${ }^{(28,31,32)}$

Notably, the results of the present study show that falls during hospitalisation, fear of falling and depression (which have been shown in previous studies to influence falls in community-dwelling individuals with stroke), ${ }^{(2,9,12,14)}$ have no influence on the incidence of falls in our study. However, as 
only simple questions regarding whether the participants were afraid of falling and whether they were depressed were asked during the telephone interviews in our study, which was conducted one year post discharge, the psychological conditions of the participants might not be sufficiently assessed. To further determine the effects of the fear of falling and depression on community-dwelling stroke individuals, the use of valid and reliable assessment tools might be required.

Multivariate logistic regression analysis revealed that only the FIM Transfer domain is a significant factor for predicting falls in our cohort. A possible explanation could be the fact that transfer, being a functional mobility task, requires many components of task execution (e.g. safety awareness, attention, motor planning, problem-solving, physical strength, static and dynamic balance and coordination) in order for the task to be performed safely and successfully. Therefore, FIM might be a good predictor of falls, as it assesses the ability of individuals with stroke to perform functional daily activities. FIM might be clinically useful, as it is now routinely used at hospital discharge to determine the current functional level of the patients. Furthermore, it is at the point of discharge that clinicians introduce essential and appropriate services to help patients transit safely and successfully back to the community.

Wagner et al, who examined the use of discharge FIM scores to predict falls in community-dwelling individuals with stroke, found that FIM could not distinguish fallers from nonfallers. ${ }^{(33)}$ However, a closer examination of their data reveals that their participants (both fallers and non-fallers) have been discharged with a relatively high FIM score (95-100). In contrast, the participants in our study were discharged at a lower functional level (median FIM score - total: 88; fallers: 72; non-fallers: 89). This may imply that the use of discharge FIM scores to predict falls is limited to stroke patients with a lower functional score.

In addition, more emphasis may be placed on the discharge FIM Transfer domain, with particular attention given to stroke individuals who achieve a score of $\leq 4$ in individual FIM Transfer items (i.e. individuals who require assistance in transfer) at the point of discharge. Based on the findings of our study, such patients are at a higher risk of falls (i.e. patients with a median score of $\leq 4$ in individual FIM Transfer items were more likely to be in the faller group). Sensitivity and specificity of a median score of $\leq 4$ in the individual discharge FIM Transfer items (i.e. a median score of $\leq 12$ in the FIM Transfer domain) in predicting falls were $38.3 \%$ and $89.4 \%$, respectively.

Our study is not without limitations. Firstly, due to the retrospective nature of our study, there may have been an underreporting of fall events, as our participants may possibly have problems recalling all the fall events during the past one year. $^{(34)}$ Secondly, the participants were discharged from a single hospital. The patients with stroke admitted into TTSHRC are of a certain case mix (e.g. a certain level of severity), and thus our study may not have captured all the different types of individuals with stroke in Singapore. Another limitation is the small sample size of the faller subgroup in our study $(n=30)$, which prevents robust data analysis. Hence, a prospective, multicentre study with a larger number of participants is recommended in order to develop a more accurate predictive model. In consideration of the risk factors of falls, it will be of value to investigate in greater detail other non-physical factors such as the fear of falling and depression. It will also be propitious to investigate the types and severity of injuries individuals with stroke sustain after falls in order to assess the magnitude of this problem in Singapore.

In conclusion, our study has shown that poor balance, reduced lower limb motor functions, reduced functional mobility and ability, as well as reduced cognitive function at the point of and after discharge, are factors associated with falls in community-dwelling individuals with stroke. Discharge FIM scores, particularly in the Transfer domain, have the potential to be developed as a predictive model for falls in communitydwelling individuals with stroke at discharge. Assessment of these discharge outcome measures will assist in the identification of individuals with stroke who have a high fall risk, and enable clinicians to implement early fall prevention management, so that fall occurrence can be minimised in the community.

\section{ACKNOWLEDGEMENTS}

The authors appreciate TTSHRC for the support and Dr Arul Earnest for the advice rendered on statistical analysis.

\section{REFERENCES}

1. Ashburn A, Hyndman D, Pickering R, Yardley L, Harris S. Predicting people with stroke at risk of falls. Age Ageing 2008; 37:270-6.

2. Belgen B, Beninato M, Sullivan PE, Narielwalla K. The association of balance capacity and falls self-efficacy with history of falling in community-dwelling people with chronic stroke. Arch Phys Med Rehabil 2006; 87:554-61.

3. Divani AA, Vazquez G, Barrett AM, Asadollahi M, Luft AR. Risk factors associated with injury attributable to falling among elderly population with history of stroke. Stroke 2009; 40:3286-92.

4. Harris JE, Eng JJ, Marigold DS, Tokuno CD, Louis CL. Relationship of balance and mobility to fall incidence in people with chronic stroke. Phys Ther 2005; 85:150-8.

5. Hyndman D, Ashburn A. Stops walking when talking as a predictor of falls in people with stroke living in the community. J Neurol Neurosurg Psychiatry 2004; 75:994-7.

6. Kerse N, Parag V, Feigin VL, et al. Falls after stroke: results from the Auckland Regional Community Stroke (ARCOS) Study, 2002 to 2003. Stroke 2008; 39:1890-3.

7. Lamb SE, Ferrucci L, Volapto S, Fried LP, Guralnik JM; Women's Health and Aging Study. Risk factors for falling in home-dwelling older women with stroke: the Women's Health and Aging Study. Stroke 2003; 34:494-501.

8. Mackintosh SF, Hill K, Dodd KJ, Goldie P, Culham E. Falls and injury prevention should be part of every stroke rehabilitation plan. Clin Rehabil 2005; 19:441-51.

9. Mackintosh SF, Hill KD, Dodd KJ, Goldie PA, Culham EG. Balance score and a history of falls in hospital predict recurrent falls in the 6 months following stroke rehabilitation. Arch Phys Med Rehabil 2006; 87:1583-9. 
10. Simpson LA, Miller WC, Eng JJ. Effect of stroke on fall rate, location and predictors: a prospective comparison of older adults with and without stroke. PLoS One [serial online] 2011; 6:e19431. Available at: www.plosone. org. Accessed October 1, 2011.

11. Yates JS, Lai SM, Duncan PW, Studenski S. Falls in community-dwellling stroke survivors: an accumulated impairments model. J Rehabil Res Dev 2002; 39:385-94.

12. Jørgensen $L$, Engstad $T$, Jacobsen BK. Higher incidence of falls in long-term stroke survivors than in population controls: depressive symptoms predict falls after stroke. Stroke 2002; 33:542-7.

13. Hyndman D, Ashburn A, Stack E. Fall events among people with stroke living in the community: circumstances of falls and characteristics of fallers. Arch Phys Med Rehabil 2002; 83:165-70.

14. Forster A, Young J. Incidence and consequences of falls due to stroke: a systematic inquiry. BMJ 1995; 311:83-6.

15. Kanis J, Oden A, Johnell O. Acute and long-term increase in fracture risk after hospitalization for stroke. Stroke 2001; 32:702-6.

16. Pouwels S, Lalmohamed A, Leufkens B, et al. Risk of hip/femur fracture after stroke: a population-based case-control study. Stroke 2009; 40:3281-5.

17. Ramnemark A, Nyberg L, Borssén B, Olsson T, Gustafson Y. Fractures after stroke. Osteoporos Int 1998; 8:92-5.

18. Weerdesteyn V, de Niet M, van Duijnhoven HJ, Geurts AC. Falls in individuals with stroke. J Rehabil Res Dev 2008; 45:1195-213.

19. Tinetti ME, Speechley M, Ginter SF. Risk factors for falls among elderly persons living in the community. N Engl J Med 1988; 319:1701-7.

20. Gladstone DJ, Danells CJ, Black SE. The Fugl-Meyer assessment of motor recovery after stroke: a critical review of its measurement properties. Neurorehabil Neural Repair 2002; 16:232-40.

21. Beninato M, Gill-Body KM, Salles $S$, et al. Determination of the minimal clinically important difference in the FIM instrument in patients with stroke. Arch Phys Med Rehabil 2006; 87:32-9.

22. Kidd D, Stewart G, Baldry J, et al. The Functional Independence Measure: a comparative validity and reliability study. Disabil Rehabil 1995; 17:10-4.
23. Blum L, Korner-Bitensky N. Usefulness of the Berg Balance Scale in stroke rehabilitation: a systematic review. Phys Ther 2008; 88:559-66.

24. Maeda N, Kato J, Shimada T. Predicting the probability for fall incidence in stroke patients using the Berg Balance Scale. J Int Med Res 2009; 37:697-704.

25. Muir SW, Berg K, Chesworth B, Speechley M. Use of the Berg Balance Scale for predicting multiple falls in community-dwelling elderly people: a prospective study. Phys Ther 2008; 88:449-59.

26. Muir SW, Berg K, Chesworth B, Klar N, Speechley M. Balance impairment as a risk factor for falls in community-dwelling older adults who are high functioning: a prospective study. Phys Ther 2010; 90:338-47.

27. Baetens T, De Kegel A, Calders P, Vanderstraeten G, Cambier D. Prediction of falling among stroke patients in rehabilitation. J Rehabil Med 2011; 43:876-83.

28. Nyberg L, Gustafson Y. Patient falls in stroke rehabilitation. A challenge to rehabilitation strategies. Stroke $1995 ; 26: 838-42$.

29. Sze KH, Wong E, Leung HY, Woo J. Falls among Chinese stroke patients during rehabilitation. Arch Phys Med Rehabil 2001; 82:1219-25.

30. Badke MB, Duncan PW. Patterns of rapid motor responses during postural adjustments when standing in healthy subjects and hemiplegic patients. Phys Ther 1983; 63:13-20.

31. Campbell GB, Matthews JT. An integrative review of factors associated with falls during post-stroke rehabilitation. J Nurs Scholarsh 2010; 42:395-404.

32. Liu-Ambrose T, Pang MY, Eng JJ. Executive functioning is independently associated with performances of balance and mobility in communitydwelling older adults after mild stroke: implications for falls prevention. Cerebrovasc Dis 2007; 23:203-10.

33. Wagner LM, Phillips VL, Hunsaker AE, Forducey PG. Falls among community-residing stroke survivors following inpatient rehabilitation: a descriptive analysis of longitudinal data. BMC Geriatr 2009; 9:46.

34. Lachenbruch PA, Reinsch S, MacRae PG, Tobis JS. Adjusting for recall bias with the proportional hazards model. Methods Inf Med 1991; 30:108-10.

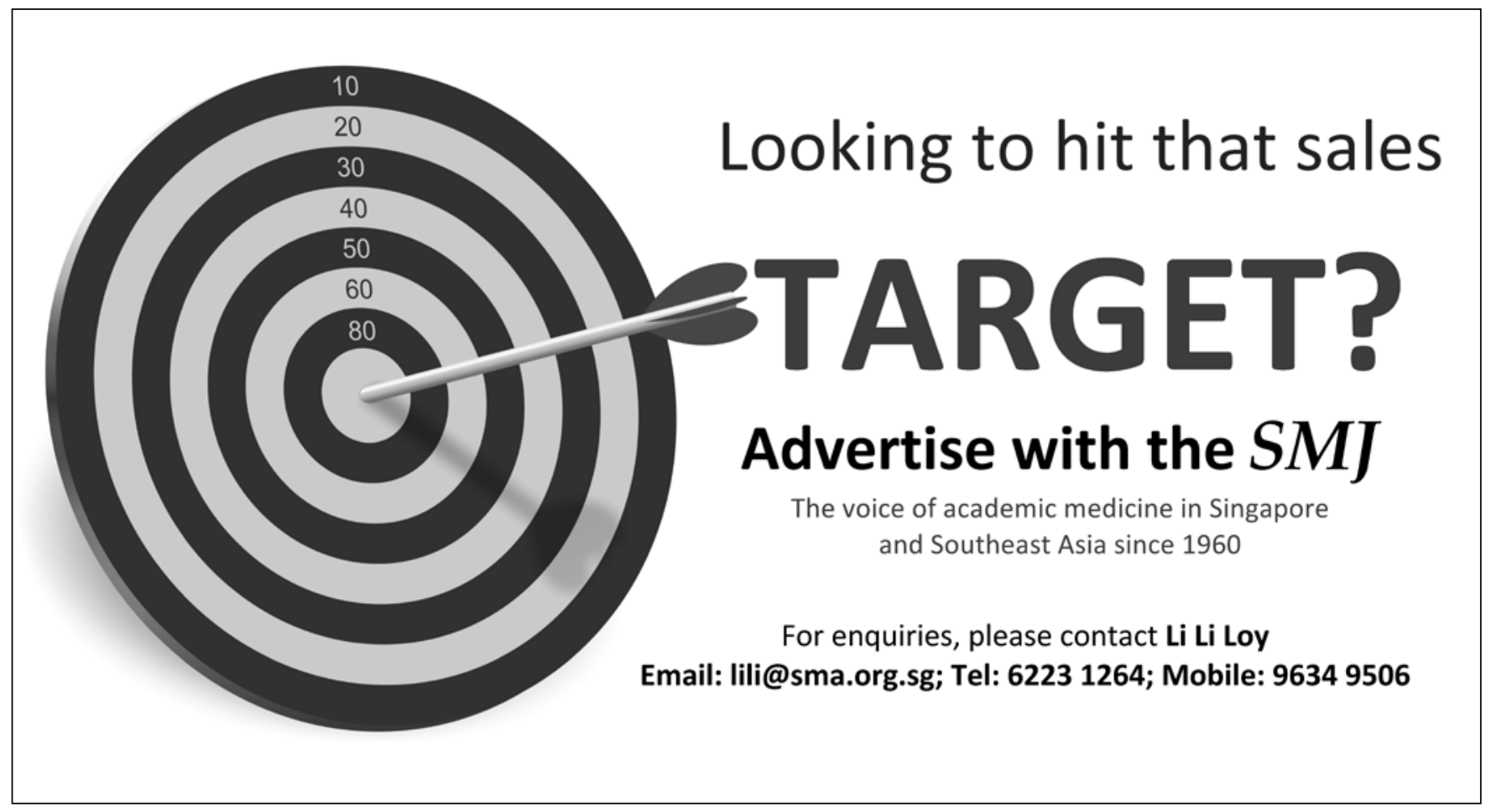

